\title{
FIRE DETECTOR SYSTEM WITH WIRELESS COMMUNICATION FOR DOMESTIC USE
}

\author{
Wongalethu Kaptein $^{1}$ Ali el-fallah ${ }^{2}$ Ali M Almaktoof ${ }^{3}$ \\ ${ }^{1}$ Department of Electrical, Electronics and Computer Engineering, Cape Peninsula University of \\ Technology \\ ${ }^{2,3}$ Department of Electrical and Electronics Engineering, Sabratha University \\ ${ }^{1}$ wongalethukaptein@gmail.com
}

\begin{abstract}
The surveillance of home places through sensors and the prevention of problems via prediction are of vital importance for the safety of these areas. Fires usually occur in homes due to inattention and changes in environmental conditions. They cause threats to the residential community and may lead to human death and property damage. Thus, house fires must be detected as early as possible to prevent these types of threats.

This study provides a simple design for a wireless fire detection network system. This system is meant to notify the household of a fire occurrence in the house by sending a short message through the Global System for Mobile Communications (GSM). In order to premonitor the possibility of a fire, the Arduino programmed board receives temperatures and humidity levels from sensors. When it detects that the collected data exceeds a predefined and precalculated threshold, it promptly communicates with the wireless system and sends an alert message to the user through the GSM.
\end{abstract}

Keywords: Fire detector, Temperature sensor, Smoke sensor, GSM, Arduino.

\section{Introduction}

Fire detection became a very big issue in the past decades, as caused severe human deaths and property damages. Thus, many efforts have been dedicated, in most developed countries, to design and develop fire detection systems (Ahrens 2011). A fire alarm system should be reliable and be able to notify household as soon as possible about the presence of fire indicators, such as smoke or high temperatures. Due to their fast response time and relatively low cost fire detectors are usually implemented in the form of smoke sensors (Müller et al. 2006). Integrating several types of sensors within the fire detector provides a more efficient fire alarm system (Cheon et al. 2009).

Conventional system methods are based on wired systems, such as CAN bus, due to the high safety in critical applications. Although bus network has greatly improved in expansibility and maintenance, wireless systems have become more attractive in recent years because of their low cost and spatial flexibility. A wireless sensor network requires sensor nodes that are small in order to facilitate the deployment and decrease power consumption since they are battery powered (Rawat \& Singh 2014). Fire detector systems 
with wireless communication are designed and built to notify a house owner of a fire by sending a short service message and triggering an alarm when a fire is detected. Temperature and Humidity sensors (DHT11) and smoke sensors (M) are used as detectors in the system to sense room temperature and smoke concentration that are present in air, respectively. Arduino Uno board, as the microcontroller, and the gsm sim900a module, are used to establish communication between the microcontroller unit and the mobile phone (Arduino 2020; Boxall 2013).

Home and industrial safety systems for fire and gas leakage detection use microcontrollers, which are featured by a sensing circuit. This circuit detects gas leakage and fire and gives an alert with the help of an alarm system. Using the GSM module sim900 within this system enables it to send a message to notify the user of such hazards. Moreover, this system is equipped with a water sprinkler to reduce the effect of the fire. The hardware of this system consists of an ATmega328 AVR microcontroller, an LCD display (16x2), a GSM module (sim900a), a buzzer, a temperature sensor (LM35), gas sensors (MQ2 and MQ9), an infrared (IR) flame sensor, and a power supply (Gajare \& Mahajan 2018).

For early detection of house fires, IOT (Based Intelligent Modelling of Smart Home Environment for Fire Prevention and Safety Systems) designed and evaluated a wireless sensor network that used multiple sensors. To avoid false alarms, they deployed the Global System for Mobile communication (GSM) and used a Fire Dynamics Simulator (FDS) that simulates fire in smart homes. This system can function accordingly, even when a sensor is not working. The hardware implementation in this system consists of a temperature sensor (LM35), a smoke sensor (MQ9), a gas sensor (MH-219 NDIR), a GSM Module and a Fire Dynamic Simulator (Saeed et al. 2018).

Wireless based on perfunctory fire detection and liberate system concentrates on monitoring and controlling of fire accidents and liberating operation for perfunctory in trains. The system consists of a temperature sensor and a gas sensor in each compartment inside the train to measure the environmental changes and to propagate the obtained information via the Global System for Mobile communication network. An automatic sprinkler system and a surveillance camera are used to reduce the fire and monitor humans' motion, respectively during the fire accident. The hardware implementation in this system is a power supply, a gas sensor, a temperature sensor, a surveillance camera, a PC, an alarm, a GSM module and a driver (Yuvaraju et al. 2016).

Fire monitoring and controlling system focuses on alerting people to evacuate a place under fire or any similar hazards. Such systems use various sensors such as flame sensors, smoke sensors, and CNG/LPG sensors to detect flames, smokes and gas leakages respectively. This system uses a microcontroller as a processor to monitor the flame, the smoke and the other sensors. When the sensor detects a fire or smoke, it sends a control signal to the microcontroller, and then the microcontroller triggers the emergency alarm. Location information of the place under fire is sent to the fire station using GSM and GPS. For on-site control, this system uses a water sprinkler. The hardware implementation in this project is an ARM LPC2148 microcontroller, a flame sensor, a smoke sensor, an 
LPG/CNG sensor, an LCD display, a GSM module Sim900, a GPS Module, a buzzer, and a water sprinkler (Gaikwad et al. 2016).

Embedded system for Hazardous Gas Detection and Alerting is a microcontroller based on a toxic gas detection and an alert system, which focuses on hazardous gas leakage detection and human lives saving. If the LPG of propane measured by the sensor exceeds the normal level (LPG>1000ppm or propane>1000ppm) an alarm is generated and a Short Message Service is sent to the authorized user, leading to a faster diffusion of emergency. The hardware implementation in this system consists of a PIC 16F877 microcontroller, a GSM module, an LCD display, a buzzer and a gas sensor (Ramya \& Palaniappan 2012).

\section{Related Work}

The technique used for developing the fire detector system in this study is different from those used in the previous studies; a comparison between the hardware used in the previous studies and the current is presented in Table (1).

Table (1): Components Used in Previous Related Studies of the Fire Detector System

\begin{tabular}{|c|c|c|c|c|c|c|c|c|c|}
\hline $\begin{array}{c}\text { Power } \\
\text { supply }\end{array}$ & MQ2 & LM35 & $\begin{array}{c}\text { GSM } \\
\text { Module }\end{array}$ & LCD & Buzzer & $\begin{array}{c}\text { IR } \\
\text { flame } \\
\text { sensor }\end{array}$ & $\begin{array}{c}\text { Water } \\
\text { Sprinkler }\end{array}$ & $\begin{array}{c}\text { Arduino } \\
\text { Uno }\end{array}$ & Studies \\
\hline$\checkmark$ & $\checkmark$ & & $\checkmark$ & $\checkmark$ & $\checkmark$ & $\checkmark$ & $\checkmark$ & $\checkmark$ & $\begin{array}{c}\text { (Gajare \& } \\
\text { Mahajan 2018) }\end{array}$ \\
\hline$\checkmark$ & $\checkmark$ & $\checkmark$ & $\checkmark$ & & $\checkmark$ & & & & $\begin{array}{c}\text { (Yaeed et al. 2018) } \\
\text { (Yuaraju et al. } \\
\text { 2016) }\end{array}$ \\
\hline & $\checkmark$ & & $\checkmark$ & $\checkmark$ & $\checkmark$ & $\checkmark$ & $\checkmark$ & & $\begin{array}{c}\text { (Gaikwad et al. } \\
\text { 2016) }\end{array}$ \\
\hline$\checkmark$ & $\checkmark$ & $\checkmark$ & $\checkmark$ & $\checkmark$ & $\checkmark$ & & $\checkmark$ & $\checkmark$ & $\begin{array}{c}\text { (Ramya \& } \\
\text { Palaniappan 2012) }\end{array}$ \\
\hline
\end{tabular}

\section{Wireless Sensor Networks}

The developed system consists of two main parts, namely hardware and software. The wireless sensor network is a combination of large sensor nodes each can sense, process, and communicate with its peers in order to work together in a cooperative manner through a microprocessor. The microprocessor here is Arduino Uno board that serves as the gateway between sensor nodes and users. In addition, a mobile application has been developed to notify the user in real time about the fire alarm.

The overall system block diagram of the fire detector system and wireless communication is shown in figure (1). It comprises a power supply unit, a battery backup system, a sensor unit, a microcontroller unit, an alert unit, a Liquid crystal display (LCD), and a GSM module connected to a mobile phone, which creates a communication path. The software 
part has been developed using $\mathrm{C}$ language on the software integrated with Arduino environment development.

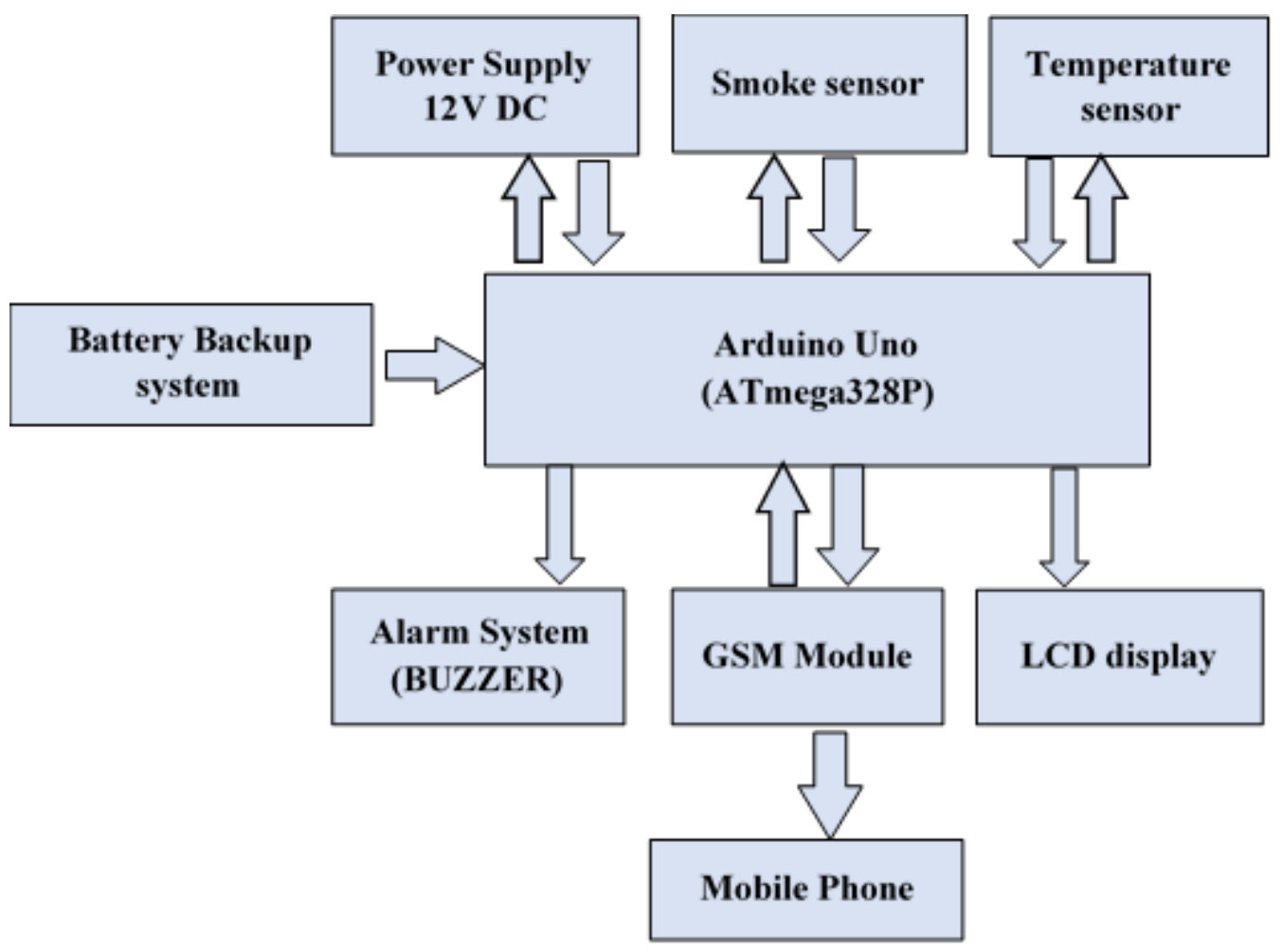

Figure (1): Block Diagram of the Fire Detector System.

\section{Hardware implementation of the fire detector system}

Figure (2.a) presents the hardware implementation of the fire detector system and figure (2.b) presents the fire detector system powered by a laptop. The insisde view of the fire detector system is depicted in figure (3).

\section{Arduino Microcontroller}

Arduino microcontrollers are used to develop interactive objects through receiving inputs from a variety of switches or sensors and controlling a variety of lights, motors, and other physical outputs. Arduino projects can stand-alone, or they can be linked to software running on computers. Arduino boards are relatively inexpensive compared to other microcontroller platforms. Figure (4) shows the Arduino Uno board (Arduino 2020; Boxall 2013).

\section{Power Supply Unit}

The power supply unit is responsible for providing power to the whole system. The Personal computer feeds power to the Arduino board which then energize the temperature sensor, smoke sensor and liquid crystal display; all the components requires only five volts to function. 


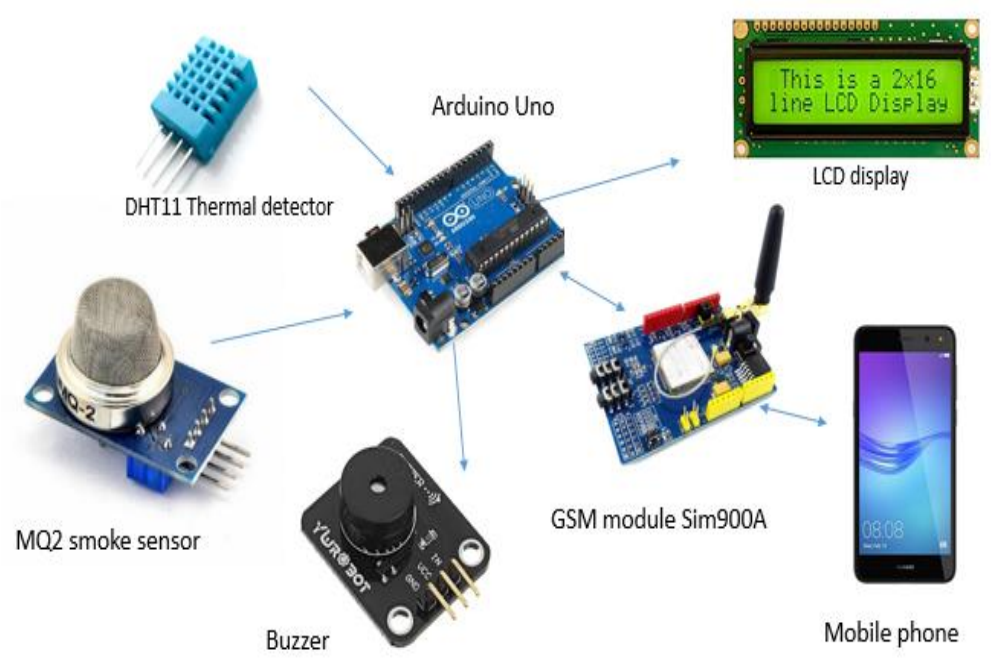

Figure (2a): Hardware Implementation of the Fire Detector System.

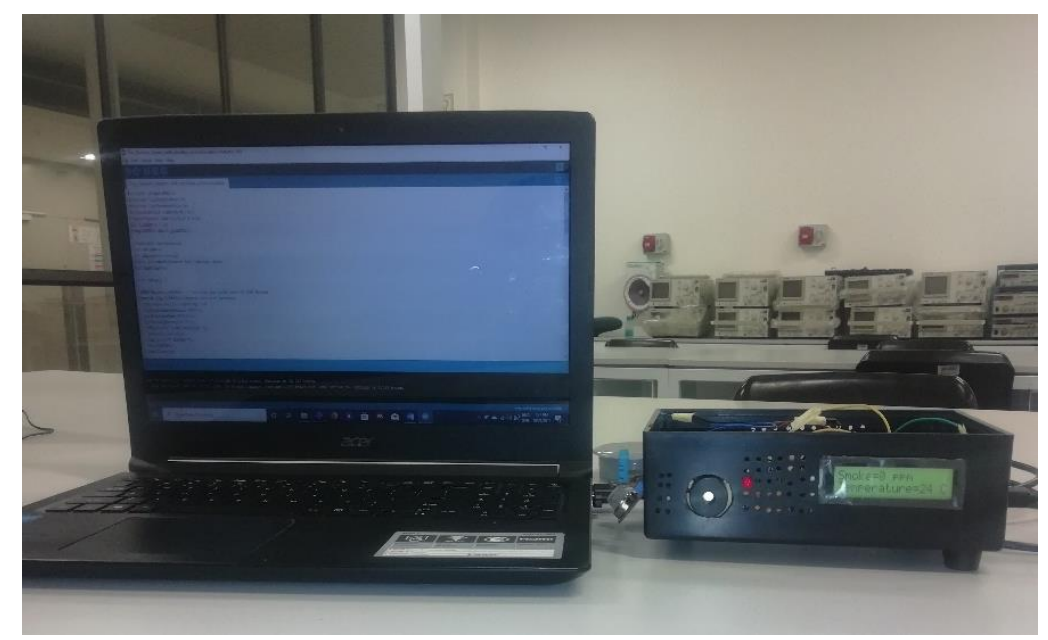

Figure (2b): The System Powered by the Personal Computer.

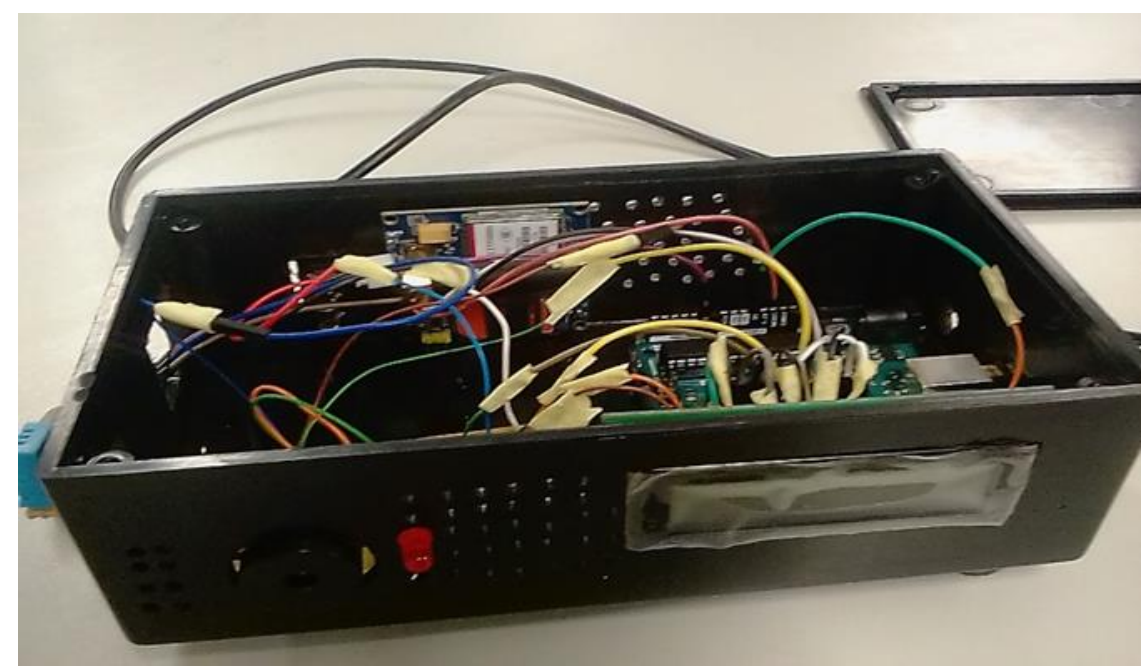

Figure (3): Insisde View of the Fire Detector System. 


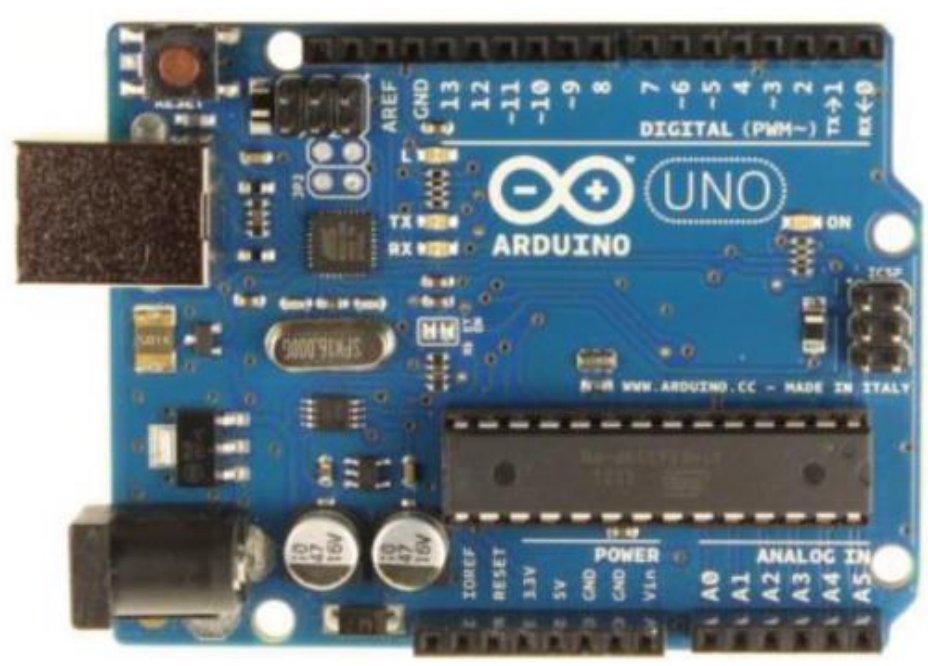

Figure (4): Arduino Uno Board.

\section{Sensing Unit}

The sensing unit consists of a temperature and humidity sensor (DHT11) and a smoke sensor (MQ2). The Digital Humidity Temperature sensor (DHT11) detects temperature rise and humidity level. The DHT11 can measure the temperature from zero to fifty degrees Celsius with \pm 5 percent. MQ2 smoke sensor has the ability to measure smoke concentration present in air. Furthermore, it is sensitive for methane, butane, and LPG, which are flammable and combustible gases. This sensor can measure concentration in the range of $300 \mathrm{ppm}$ to $1000 \mathrm{ppm}$.

\section{Microcontroller Unit}

The Arduino microcontroller is used for processing the data of the two sensors. The Arduino is responsible for communication among the other modules of the system.

\section{Alarm Unit}

Piezoelectric buzzer is a low cost dependable device, which is used to generate an alarm tone in electronic circuits. The piezoelectric buzzer is interfaced with the microcontroller to send a tone out when a fire is detected.

\section{Alert Unit}

The alert unit is the GSM module sim900a, which sends a short service message (SMS) to the user mobile number. The GSM module communicates with the microcontroller through a Universal asynchronous receiver and a transmitter.

\section{Visual Alert Unit}

The visual alert unit is the Liquid Crystal Display, which displays the room temperature and smoke concentration measured by the temperature sensor and smoke sensor, respectively. 


\section{Software Development}

The algorithm for the fire detector system was developed and implemented on the Arduino integrated development environment (IDE) software. Figure (5) presents the flow algorithm flow chart of the fire detector system.

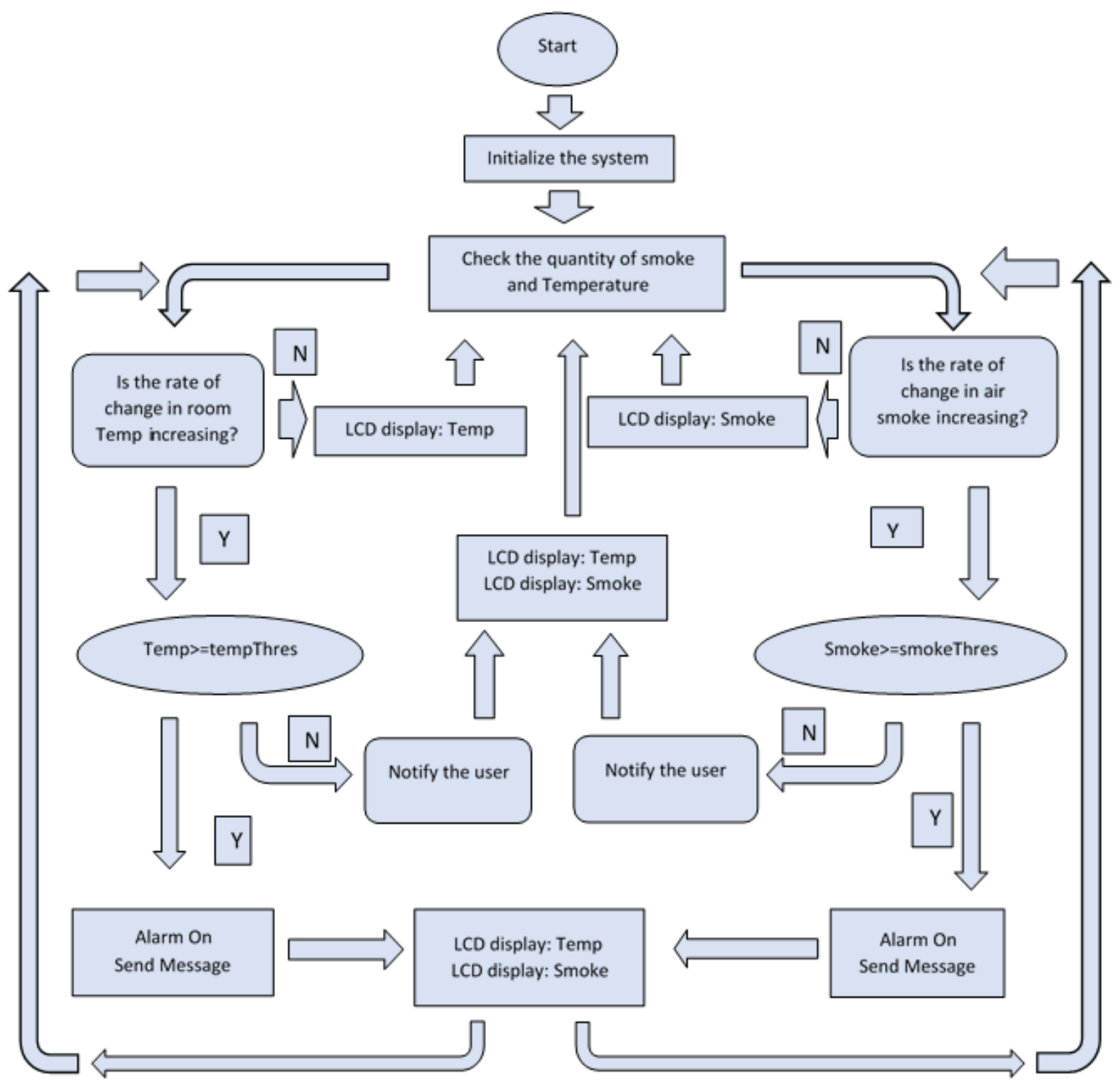

Figure (5): Algorithm Flow Chart of the Fire Detector System.

The software design of the fire detector system has been divided into the following sections:

1. LCD program.

2. DHT11 sensor program.

3. MQ2 sensor program.

4. GSM sim900A module program. 


\section{Liquid Crystal (LCD) Display Program}

The following code is responsible for displaying the sensors results.

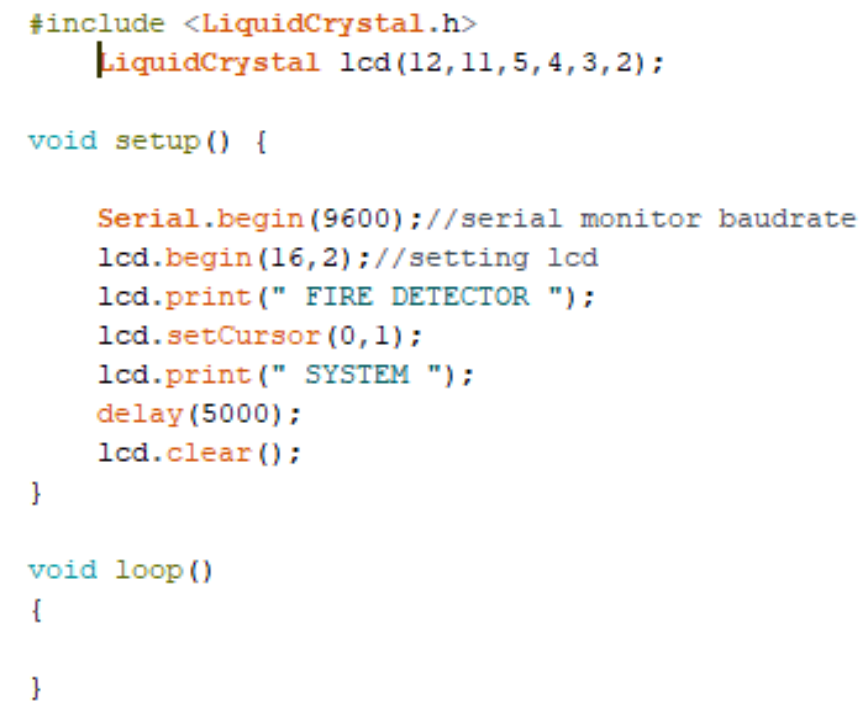

\section{DHT11 Sensor Program}

This section of the code is responsible for temperature measuring.

\section{MQ2 Sensor Program}

This section of the code is responsible for smoke concentration measuring.

\section{GSM Sim900A Module Program}

It is responsible for sending a Short Message Service. The folowing section of the code for sim900A module program. 


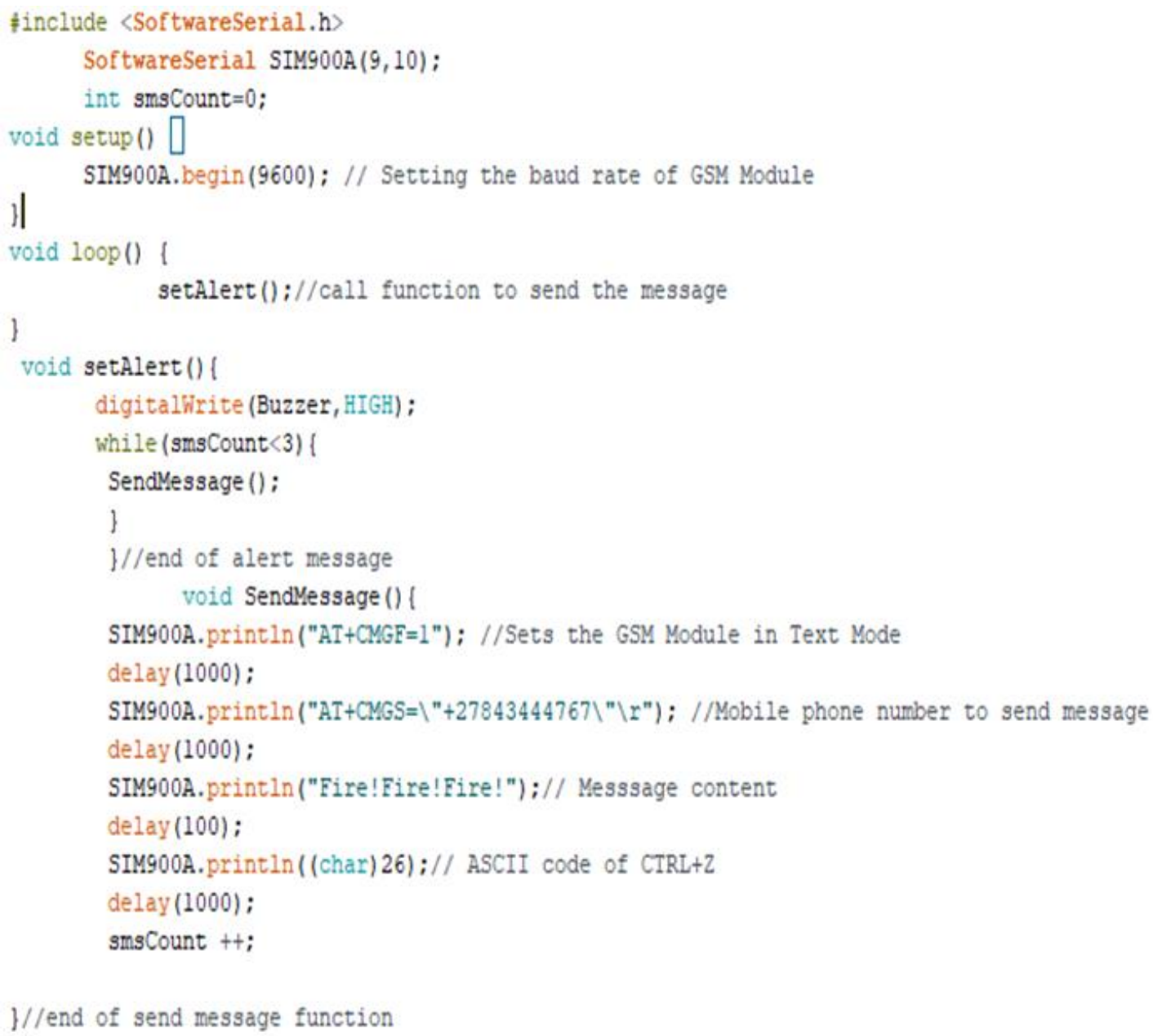

\section{Results and Discussion}

This section covers the implementation and testing phases of the fire detector system. Performance testing is presented on Table (2). This test has been performed to determine the amount of time it takes for the user to receive a message when a fire is detected. Figure (6) shows the alert messages sent to the mobile phone.

Table (2): Performance Testing

\begin{tabular}{|c|c|}
\hline Alert name & Time before text arrived \\
\hline Alert 1 & 3 seconds \\
\hline Alert 2 & 2 seconds \\
\hline Alert 3 & 2 seconds \\
\hline Alert 4 & 2 seconds \\
\hline
\end{tabular}




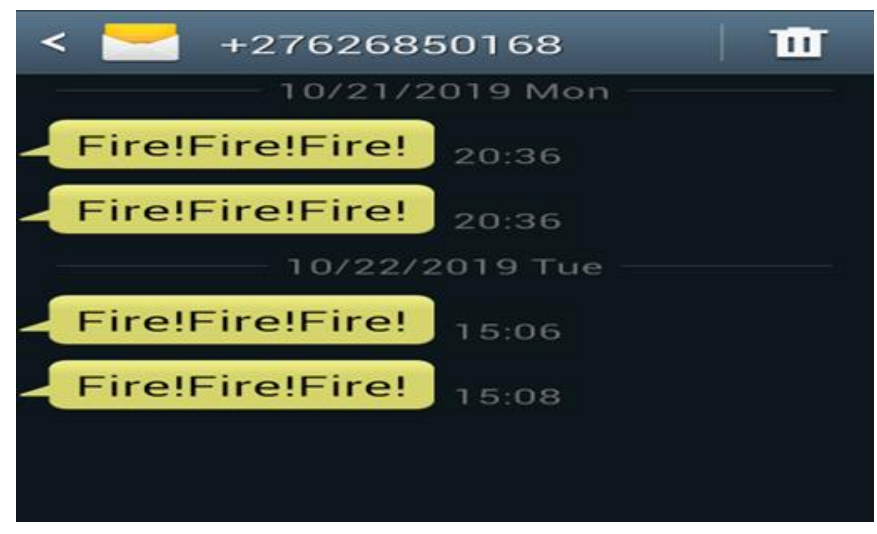

Figure (6): Screenshot of the Alert Messages Sent to the Mobile Phone (Samsung Galaxy S2).

It can be seen on from figure 5 that the results of the application meet the motive of the system. All the messages, which were sent via the GSM module, were delivered within a 5 seconds to the mobile station (mobile phone).

The system was tested and evaluated under different conditions: firstly, normal environment condition i.e. when there was no smoke, and heat and temperature were within the allowed range, secondly, when only smoke was applied to the fire detector and finally when heat and smoke were applied to the system.

\section{Integration Testing (System Testing)}

To see how the entire system performs, a complete test was done. During this test a lighter and a piece of paper was used. The lighter was used to produce heat and a piece of paper was used to produce the smoke. Figure (7) shows fire detector system response in normal environment. Figure (8) shows fire detector system response in a smoke dominated environment. Figure (9) shows fire detector system response in a heat and smoke dominated environment.

\section{A: Test Type 1}

Normal environment. The system response in normal environment as shown in Figure (7).

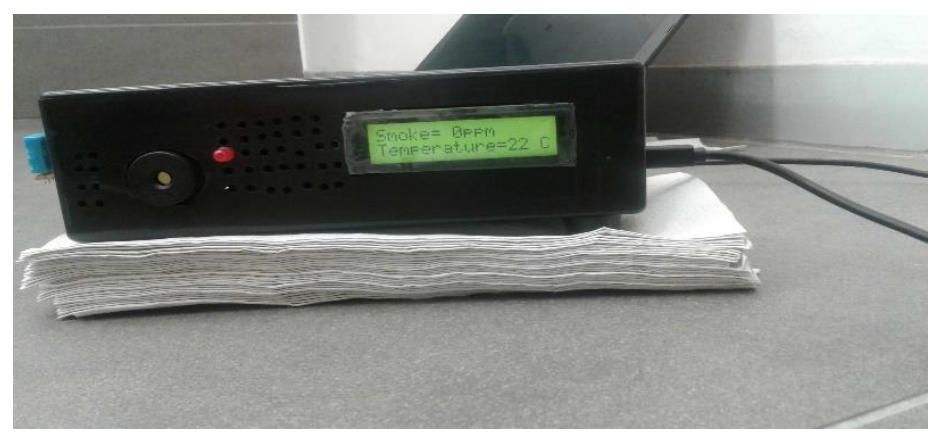

Figure (7): Fire Detector System Response in Normal Environment. 


\section{B: Test Type 2}

When only smoke was applied on the fire detector as depicted in Fgure (8).

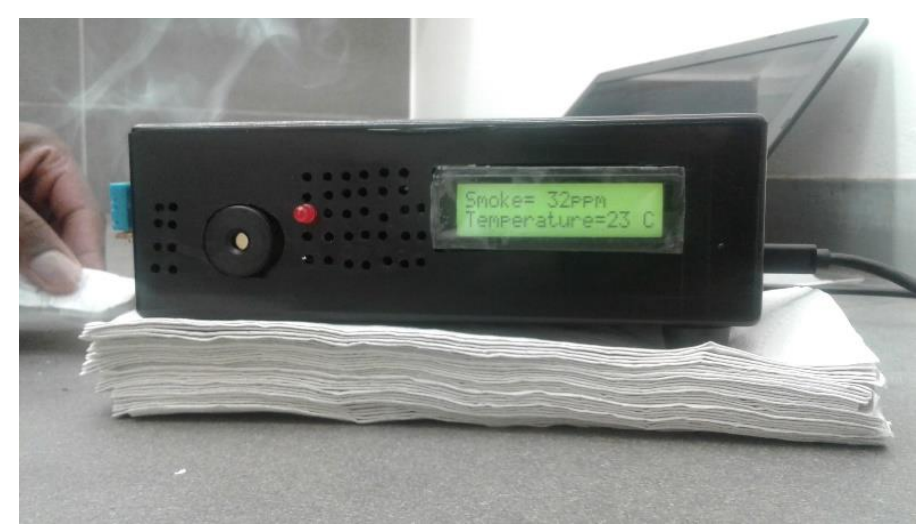

Figure (8): Fire Detector System Response in a Smoke Dominated Environment.

\section{C: Test type 3}

Heat and smoke were applied to the system as shown in Figure (9).

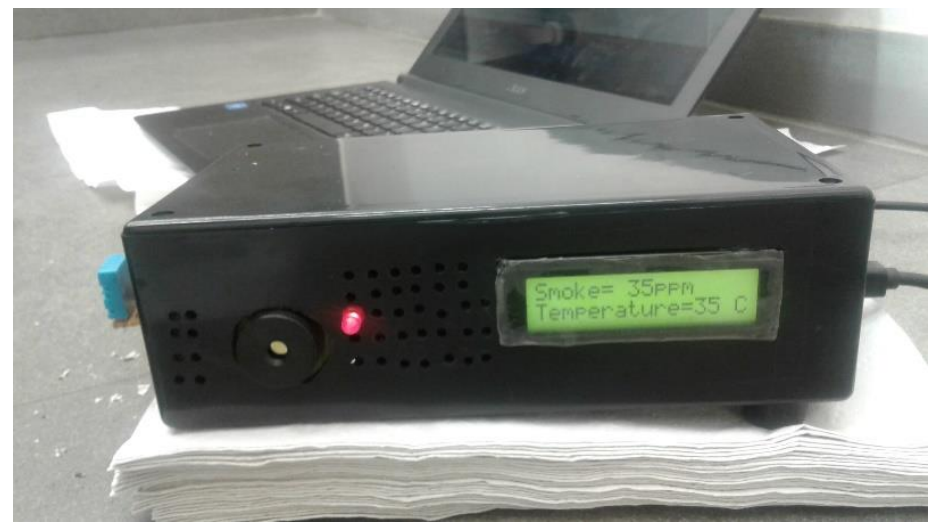

Figure (9): Fire Detector System Response in a Heat and Smoke Dominated Environment.

\section{Conclusions and Recommendations}

\section{Conclusion}

Wireless sensor networks play a significant role in real environment. The developed sensing device uses a combination of a smoke sensor and temperature sensors to provide better fire alarm detection. Such a device can reduce false-alarm rates and provide high reliability. The purpose of integrating the GSM communication module was to provide a prompt alert of fires. 
The results and evaluations showed that the proposed system satisfies all the desired requirements and can be used as a domestic as well as industrial setting for detecting a starting fire.

\section{References}

- Ahrens, M. 2011, Smoke Alarm Presence and Performance in U.S. Home Fires. Fire Technol. 47, 699-720.

- Arduino, [Online]. Available: http://www.arduino.cc, (C) 2020 Arduino [Accessed 0201 2020].

- Boxall, John. 2013, "Arduino Workshop: A Hands-on Introduction with 65 Project", Publisher: William Pollock, ISBN-10: 1-59327-448-3.

- Cheon, J.; Lee, J.; Lee, I.; Chae, Y.; Yoo, Y.; Han, G. 2009, A single-chip CMOS smoke and temperature sensor for an intelligent fire detector. IEEE Sens. J. 9, 914-920.

- Gaikwad, K. M., Quadri, A., Akshada, S., and Reshma, Z. 2016, Fire monitoring and control system, Research Journal of Engineering and Technology, vol. 3, Issue 5, pp. 18001802 .

- Gajare, R. S., Mahajan, P. 2018, Home and Industrial safety system for fire and leakage detection, International Research Journal of Engineering and Technology, vol. 5, Issue 7, pp. 1286-1292.

- Müller, K.; Loepfe, M.; Wieser, D. 2006, Optical simulation for fire detectors. Fire Safety J. 41, 274-278.

- Ramya, V., Palaniappan, B. 2012, Embedded system for Hazardous Gas detection and Alerting, International Journal of Distributed and Parallel system, vol. 3, no. 1, pp. 287300 .

- Rawat, P.; Singh, K.D.; Chaouchi, H.; Bonnin, J.M. 2014, Wireless sensor networks: A survey on recent developments and potential synergies. J. Supercomput. 68, 1-48.

- Saeed, F., Paul, A., Rehman, A., Hong, W. H. and Seo, H. 2018, IoT-Based Intelligent Modelling of Smart Home Environment for fire prevention and safety, Journal of Sensor and Actuator Networks, pp.1-16.

- Yuvaraju, M., Naraina, A. and Deepika, K. 2016, Based on Perfunctory Fire Detection and Liberate system, International Journal of Engineering and Technology, vol. 3, Issue 6, pp. 468-472. 